\title{
Carpal Tunnel Syndrome Prevalence and Characteristics among Administrative Staff at Dr.Hasan Sadikin General Hospital Bandung
}

\author{
Andrian, ${ }^{1}$ Nushrotul Lailiyya, ${ }^{2}$ Novitri $^{3}$ \\ ${ }^{1}$ Faculty of Medicine Universitas Padjadjaran, ${ }^{2}$ Department of Neurology Faculty of Medicine, \\ Universitas Padjadjaran/Dr. Hasan Sadikin General Hospital, Bandung, ${ }^{3}$ Department of Physical \\ Medicine and Rehabilitation Faculty of Medicine Universitas Padjadjaran/Dr. Hasan Sadikin \\ General Hospital, Bandung
}

\begin{abstract}
Background: Carpal tunnel syndrome (CTS) is a neurologic disease affecting hands, which is closely related to work, and is the most prevalent nerve compression disease. The incidence of CTS quite often occur in people working with their hands, for instance the administrative staff, especially in a busy workplace such as Dr.Hasan Sadikin General Hospital Bandung. CTS causes reduction in work productivity, and consequently degrading family welfare and the quality of public service. For that very reason, the prevalence and characteristics of CTS among administrative staff at Dr.HasanSadikin General Hospital Bandung needed to be revealed.

Methods: This quantitative descriptive study involved 94 administrative staff in the Medical record department of Dr. Hasan Sadikin General Hospital using the Carpal-tunnel.net questionnaire and further examinations by neurologists. Variables involved in this study were the subject characteristics.

Results: Out of the 90 subjects, 22 stated having symptoms related to CTS (prevalence, 24.4\%). On further clinical examination, 3 were diagnosed of suffering from CTS (prevalence, 3.3\%).

Conclusions: Carpal tunnel syndrome is found among the administrative staff at Dr. Hasan Sadikin General Hospital Bandung and the prevalence is lower than in the general population. A further study is required to reveal ther specific division in the hospital with the most prevalent CTS case.
\end{abstract}

Keywords: Administrative staff, carpal tunnel syndrome, Hasan Sadikin, prevalence

\section{Introduction}

Carpal Tunnel Syndrome (CTS) is the most prevalent median nerve disease, and also the most prevalent nerve entrapment syndrome, with the estimation that $3.8 \%$ of the world population is affected. ${ }^{1}$ Risks for CTS are related to work, and CTS is often ascribed as an occupational disease. ${ }^{2,3}$ Administrative work, especially in busy workplaces, is one of the jobs with highest CTS occurrence, along with other jobs such as secretarial, construction work, and production. ${ }^{4}$

Aside from physical and functional loss, people with CTS also suffer financial loss. Furthermore, a study in Washington State affirmed a significant financial loss is suffered by people with CTS each year, and the study underlined the significance of CTS prevention in workplace. ${ }^{3,5,6}$ According to information from the Human Resources Division of Dr. Hasan
Sadikin General Hospital Bandung, currently, there are approximately 3000 administrative staff working every day at Dr. Hasan Sadikin General Hospital, and a study stated that 3.8\% of the general population are affected by CTS, which means, approximately 114 out of 3000 administrative staff have CTS and the number will increase if prevention is neglected. ${ }^{1,6}$

Prevention needs to be performed, otherwise CTS will cause reduction in the sufferer's family well-being and downgrade public service efforts. ${ }^{3}$ Nevertheless, not one study has been conducted on CTS occurrence and characteristics among the administrative staff at Dr. Hasan Sadikin General Hospital Bandung. Due to those reasons, this study was conducted.

\section{Methods}

This study used the quantitative descriptive

Correspondence: Tara Zhafira, Faculty of Medicine, Universitas Padjadjaran, Jalan Raya Bandung-Sumedang Km.21, Jatinangor, Sumedang, Indonesia, Phone: +6281311349612 Email: tarazhafira@yahoo.com 
method with cross sectional design. This study was approved by Dr. Hasan Sadikin General Hospital Bandung and the Health Research Ethics Committee Faculty of Medicine, Universitas Padjadjaran according to Ethical Clearance Letter No. LB.04.01/A05/ EC/263/VII/2015. The study population was all administrative staff working at Dr. Hasan Sadikin General Hospital Bandung. Sample was taken from all administrative staff working in the Medical Record Division, which is one of the busiest hand-involving administrative jobs in the hospital, making it a high risk job for CTS. There were 94 workers in the Medical Record Division; however four workers were inaccessible. Two of them were taking holiday, one was sick, and the last one was unwilling to participate in this study. This study was conducted at all medical record offices and the Department of Neurology, Dr. Hasan Sadikin General Hospital Bandung in SeptemberDecember 2015.

The study was initiated by conducting interviews and educating all medical record administrative staff regarding CTS. Those who stated having symptoms related to CTS during the interview were reffered to a further interviewed using the Carpal-tunnel. net questionnaire. The questionnaire was a validated self-administered questionnaire, developed by Bland et al. ${ }^{7}$ to be used by people with hands symptoms that were related to CTS. The questionnaire was used as interview material in this study with the author's consent.

The questionnaire contained questions regarding the subject's characteristics such as gender, age, smoking history, computer use, and handedness. Symptom characteristics, such as presence of pain, numbness, tingling, muscle weakness, persistency of symptom, and bilateral symptom are also contained in the questionnaire. The result of the questionnaire was a probability score of the subject having CTS.

It was suggested by the creator of the questionnaire to use a cut-off point of $20 \%$, instead of $40 \%$ which was originally used by the author, in this study, so the subjects who scored over 20\% were referred to the Department of Neurology for further examinations which consisted of history taking and provocative tests. The provocative tests comprised Phalen test, Tinnel test, carpal compression test, and hand elevation test. The examination was conducted by neurologists and the positive result was established when at least one provocative test was positive.
Furthermore, Phalen test was conducted by asking the subject to bend both wrists so that the dorsal part of the hands were in contact with each other for 60 seconds, positive result was established if the subject experienced tingling or numbness in the part of the hand innervated by the median nerve. Tinnel test was conducted by performing percussion over the carpal tunnel. Positive result was established if the subject experienced tingling in the part of the hand innervated by the median nerve. Carpal compression test was conducted by pressing the part of the hand between thenar and hypothenar eminences of the wrist for 30 seconds. Positive result was established if the subject experienced any CTS symptoms during the test. The hand elevation test was conducted by requesting the subject to lift both hands upright for 2 minutes. Positive result was established if the subject experienced any CTS symptoms during the test, which was later analyzed using percentage to discover the prevalence.

\section{Results}

Out of 94 subjects included in this studyt only 90 subjects were accessible.

There was no significant difference in the number of male and female subject in this study, causing the gender variable proportional in number. The numberof male subjects was higher than the female. The higher proportion of medical record administrative staff was less than 40 years old, causing more staff members were not in the high risk age for CTS, and this may affect the result of CTS prevalence within the staff (Table 1).

Twenty two staff members who stated having hand symptoms were further interviewed using the Carpal-tunnel.net questionnaire. The rest of the subjects were

\section{Table 1 Distribution of Respondent's Characteristics}

\begin{tabular}{lc}
\hline \multicolumn{1}{c}{ Variable } & $\begin{array}{c}\text { Amount of Subject } \\
\mathbf{n = 9 0}(\%)\end{array}$ \\
\hline Gender & \\
Male & $46(51.1)$ \\
Female & $44(48.9)$ \\
Age (years old) & \\
$<40$ & $69(77.7)$ \\
$\geq 40$ & $21(22.3)$ \\
\hline
\end{tabular}


taken as negative subjects because CTS is mainly a symptomatic disease, although a study by Naseer et al. ${ }^{8}$ stated that CTS may be asymptomatic.

Six males and sixteen females stated of having a hand symptom, with fifteen out of the twenty two subjects were below 40 years in age, which is not a high risk age for CTS. The bigger proportion of non-high risk age subjects can be resulted from the initial bigger proportion of non-high risk age subjects before the interview was conducted (Table 2).

Most of the subjects experienced bilateral symptoms. Nearly all subjects interviewed had intermittent symptoms, leaving only one subject with a persistent symptom.

The most prevalent symptoms experienced by the subjects were tingling, pain during the day, muscle weakness, pain during the night, and numbness respectively. Those symptoms are consistent with the symptoms described in a previous study by Atroshi et al. ${ }^{1}$

After the second interview, there were only three subjects with CTS probability score above $20 \%$ and needed to be referred for further examination (Table 3).

The examination by the neurologist verified the three subjects referred for having CTS, and it was concluded that the prevalence of CTS at Dr. Hasan Sadikin General Hospital Bandung was $3.3 \%$.

All three subjects were diagnosed as having bilateral CTS and had intermittent symptoms, which is indicative for mild CTS. ${ }^{9}$ The main symptom from the three positive subjects was tingling. Two females were diagnosed as having CTS. The three subjects with positive CTS were over 40 years old (Table 4 ).

\section{Discussions}

The study discovered that 2 out of 3 subjects

\section{Table 2 Characteristic Distribution of Respondents with CTS-related Symptoms}

\begin{tabular}{lc}
\hline \multicolumn{1}{c}{ Variable } & Amount of Subject \\
\hline Gender & \\
Male & 6 \\
Female & 16 \\
Age (year) & \\
$<40$ & 15 \\
$\geq 40$ & 7 \\
\hline
\end{tabular}

Table 3 Symptom Distribution of Respondent's Symptoms Related to CTS

\begin{tabular}{|c|c|}
\hline Variable & $\begin{array}{l}\text { Amount of } \\
\text { Subject/ } \\
\text { Frequency }\end{array}$ \\
\hline \multicolumn{2}{|l|}{ Bilaterality } \\
\hline Yes & 13 \\
\hline No & 9 \\
\hline \multicolumn{2}{|l|}{ Symptom persistency } \\
\hline Persistent & 1 \\
\hline Intermittent & 21 \\
\hline \multicolumn{2}{|l|}{ Symptom description } \\
\hline \multicolumn{2}{|l|}{ Pain during the day } \\
\hline Only right hand & 5 \\
\hline Only left hand & 2 \\
\hline Both hands & 2 \\
\hline No pain during the day & 13 \\
\hline \multicolumn{2}{|l|}{ Pain during the night } \\
\hline Only right hand & 5 \\
\hline Only left hand & 0 \\
\hline Both hands & 2 \\
\hline No pain during the night & 15 \\
\hline \multicolumn{2}{|l|}{ Numbness } \\
\hline Only right hand & 3 \\
\hline Only left hand & 2 \\
\hline Both hands & 1 \\
\hline No numbness & 16 \\
\hline \multicolumn{2}{|l|}{ Tingling } \\
\hline Only right hand & 6 \\
\hline Only left hand & 1 \\
\hline Both hands & 12 \\
\hline No tingling & 3 \\
\hline \multicolumn{2}{|l|}{ Muscle weakness } \\
\hline Only right hand & 4 \\
\hline Only left hand & 1 \\
\hline Both hands & 2 \\
\hline No muscle weakness & 15 \\
\hline
\end{tabular}

with CTS were female, although the initial portion of subject's gender is proportional. ${ }^{1,10}$ This is consistent with other literatures stating that CTS is more prevalent in women. . $^{1,6,10,11}$ 
Table 4 Distribution of Respondent's Characteristic, Symptom, \& Physical Exam

\begin{tabular}{|c|c|c|c|c|c|c|}
\hline \multirow{2}{*}{ Variable } & \multicolumn{2}{|c|}{ Subject 1} & \multicolumn{2}{|c|}{ Subject 2} & \multicolumn{2}{|c|}{ Subject 3} \\
\hline & Right Hand & Left Hand & Right Hand & Left Hand & Right Hand & Left Hand \\
\hline \multicolumn{7}{|l|}{ Examination } \\
\hline Tinnel & + & + & + & + & + & + \\
\hline Phalen & - & + & + & - & + & + \\
\hline Carpal compression & + & + & + & - & + & + \\
\hline Hand elevation & + & + & + & - & + & + \\
\hline Diagnosis & \multicolumn{2}{|c|}{ Bilateral CTS } & \multicolumn{2}{|c|}{ Bilateral CTS } & \multicolumn{2}{|c|}{ Bilateral CTS } \\
\hline \multicolumn{7}{|l|}{$\begin{array}{l}\text { Symptom } \\
\text { Description }\end{array}$} \\
\hline Pain during the day & - & - & - & - & + & - \\
\hline Pain during the night & - & - & - & - & + & - \\
\hline Numbness & - & - & - & - & + & - \\
\hline Tingling & + & + & + & + & + & - \\
\hline Muscle weakness & - & - & - & - & - & - \\
\hline Bilateral symptom & \multicolumn{2}{|c|}{ Yes } & \multicolumn{2}{|c|}{ Yes } & \multicolumn{2}{|c|}{ No } \\
\hline Persistency & \multicolumn{2}{|c|}{ Intermittent } & \multicolumn{2}{|c|}{ Intermittent } & \multicolumn{2}{|c|}{ Intermittent } \\
\hline \multicolumn{7}{|l|}{$\begin{array}{l}\text { Subject } \\
\text { Characteristics }\end{array}$} \\
\hline Gender & \multicolumn{2}{|c|}{ Female } & \multicolumn{2}{|c|}{ Male } & \multicolumn{2}{|c|}{ Female } \\
\hline Age (year) & \multicolumn{2}{|c|}{48} & \multicolumn{2}{|c|}{57} & \multicolumn{2}{|c|}{53} \\
\hline
\end{tabular}

Ninety four subjects in this study were mostly under 40 years old, which is a non-high risk age for CTS. This study discovered that all positive subjects were above 40 years old, although the initial proportion of subject's age was higher in the age below 40 years .

Three subjects examined by a neurologist were all diagnosed as having bilateral CTS, although one positive subject did not report any symptom on the left hand, supporting the study stating the presence of asymptomatic CTS. ${ }^{8}$

A previous study by Atroshi et al. ${ }^{1}$ stated that bilateral symptom commonly occurs in CTS, it was supported by the finding of two out of the three subjects having bilateral symptoms and the diagnosis of all three subjects as bilateral CTS in this study.1The most prevalent symptom reported by positive subjects was tingling, and this was consistent with the previous study stated earlier.

The results showed the prevalence of CTS among administrative staff at Dr. HasanSadikin General Hospital Bandung was 3.3\% (3 out of 90 subjects) which was close but lower than the general world population prevalence discovered by Atroshi et al. ${ }^{1}$ which is $3.8 \%$. The prevalence in this study may be lower due to many factors. One important factor is age, $77 \%$ of all medical record administrative staff were under 40 years old, making most of them excluded from the high risk age for CTS.

Other factors causing difference in the prevalence result may be the number of subject, design, and method. The study conducted by Atroshi et al. ${ }^{1}$ involved 2466 subjects, which was a lot more than this study, causing the study to have a high variation in the subject variable, besides the design of the study conducted by Atroshi et al. ${ }^{1}$ was a case control, giving the study the ability to compare variables (between case and control), identify risk factors, and a giving the study a greater and broader case definition.

The study by Atroshi et al. ${ }^{1}$ was conducted by sending mails to the subjects containing inquiries about symptoms. Two months later, the responders with and without symptoms (as a control) were clinically examined and underwent Nerve Conduction Studies 
(NCS), which is a more sensitive and specific examination for CTS than provocative tests. In addition, the two months' time given to the respondents to fill in the inquiries gave them a longer time for symptoms recall than a direct interview.

The limited sample taken only from the Medical Record Division was the limitation of this study, as it might not cover all kinds of administrative work in the hospital. In addition, the amount of time needed to complete the Carpal-tunnel.net questionnaire (approximately 30 minutes) might affect the answers of the subjects and bias the result of this study. With the informed limitations of this study, the researcher advises that future studies should cover more or all kinds of administrative work at Dr. Hasan Sadikin General Hospital Bandung and it recommends that a further study on revealing the administration division with the highest risk for CTS should be conducted. If the further study would use the Carpal-tunnel. net questionnaire, the interviewer should be confident that the subjects are not answering perfunctorily.

This study concluded that CTS occurs among Dr. HasanSadikin General Hospital Bandung administrative staff, and it amplifies the evidence of other literatures regarding the characteristics and epidemiology of CTS.

\section{References}

1. Atroshi I, Gummesson C, Johnsson R, Ornstein E, Ranstam J, Rosén I. Prevalence of carpal tunnel syndrome in a general population. JAMA. 1999;282(2):153-8.

2. Dale AMP, Harris-Adamson CP, Rempel DMD, Gerr FMD, Hegmann KMD, Silverstein $\mathrm{BP}$, et al. Prevalence and incidence of carpal tunnel syndrome in US working populations: pooled analysis of six prospective studies. Scand J Work Environ Health. 2013;39(5):495-505.
3. Foley M, Silverstein B, Polissar N. The economic burden of carpal tunnel syndrome: long-term earnings of CTS claimants in Washington State. Am J Ind Med. 2007;50(3):155-72.

4. Giersiepen K, Spallek M. Carpal Tunnel Syndrome as an Occupational Disease. Dtsch Arztebl Int. 2011;108(14):238-42.

5. Roquelaure YMD, Ha CMD, Fouquet NM, Descatha AMD, Leclerc AP, Goldberg MMD, et al. Attributable risk of carpal tunnel syndrome in the general population implications for intervention programs in the workplace. Scand J Work Environ Health. 2009;35(5):342-8.

6. Bardeesi A, Al-Twair A, Al-Mubarek A. Prevalence of Carpal Tunnel Syndrome (CTS) among medical laboratory staff at King Saud University Hospitals, KSA. BMC Proceedings. 2015;9(Suppl 1):A55.

7. Bland JDP, Rudolfer S, Weller P. Prospective analysis of the accuracy of diagnosis of carpal tunnel syndrome using a web-based questionnaire. BMJ Open. 2014;4(8):1-6.

8. Naseer, Sabah A-M, Thaier A-R, AlHusseiny. Electrophysiological changes of ssymptomatic carpal tunnel syndrome in Patients with rheumatoid arthritis: frequency distribution and correlation to disease-related factors. Med J Babylon. 2014;9(2):267-280.

9. Gelberman RH, Rydevik BL, Pess GM, Szabo RM, Lundborg G. Carpal tunnel syndrome. A scientific basis for clinical care. Orthop Clin North Am. 1988;19(1):115-24.

10. Harris-Adamson C. Biomechanical risk factors for carpal tunnel syndrome: a pooled study of 2474 workers. Occup Environ Med. 2014;72(1):33-41.

11. Nathan PA, Istvan JA, Meadows KD. A longitudinal study of predictors of research-defined carpal tunnel syndrome in industrial workers: findings at 17 years. J Hand Surg Br. 2005;30(6):593-8. 